\title{
CONSENTIMENTO INFORMADO: O DESAFIO MÉDICO-JURÍDICO DE NOSSOS DIAS
}

\author{
INFORMED CONSENT: A MEDICAL AND LEGAL CHALLENGE OF OUR TIME
}

\section{RESUMO}

Objetivos: Avaliar a real importância de se obter o consentimento informado, em formulário apropriado, e o papel deste no desfecho de ações indenizatórias. Métodos: A letra da lei brasileira e jurisprudência existente atualmente foram comparadas com o decisão judicial do Tribunal de Justiça do Estado do Rio de Janeiro, em 269 casos de ação civil indenizatória contra profissionais de saúde e hospitais. Resultados: Favoráveis (absolvições) e desfavoráveis (condenações) foram comparadas e possíveis variações em seus resultados foram discutidas quanto à existência, ou não, do termo de consentimento informado. Conclusões: A obtenção do consentimento informado, em formulários apropriados, ainda não é usual nem na área de saúde nem na jurídica brasileiras. É recomendado que essa prática seja adotada de acordo com os termos descritos neste trabalho, uma vez que este foi escrito nos termos da lei brasileira.

Descritores - Consentimento informado; Bioética; Avaliação

\section{INTRODUÇÃO}

Nos idos de 1767, na Inglaterra, o sr. Slater, objetivando dar continuidade ao tratamento de uma fratura em sua perna, dirigiu-se ao Dr. Baker, o qual trabalhava junto com o Dr. Stapleton, objetivando obter uma solução à sua patologia. Os dois médicos, entretanto, à completa revelia de seu paciente, em uma época em que sequer existia anestesia, refraturaram propositalmente o membro, para testarem uma nova técnica cirúrgica de uso não convencional, para provocar tração durante todo o processo de consolidação.

Tal feito, gerou sequelas ao paciente, as quais não foram sequer abordadas como riscos inerentes ao procedimento feito, tão pouco pedindo autorização para fazê-lo.

\section{ABSTRACT}

Objective: To assess the real importance of obtaining informed consent, through an appropriate form, and its role in the outcome of civil liability claims. Methods: The wording of the existing Brazilian law and jurisprudence were compared with the actual rulings of the State Court of the State of Rio de Janeiro State, in 269 civil liability claims against healthcare professionals and hospitals. Favorable and unfavorable outcomes (i.e. acquittals and convictions) were compared, and possible variations in the verdicts were discussed in relation to whether informed consent forms had been filled out or not. Conclusions: Obtaining informed consent, by means of appropriate forms, is still not a widespread practice in the Brazilian healthcare or judicial systems. It is recommended that this practice be adopted in the manner described in this paper, and as prescribed in Brazilian law.

Keywords - Informed consent; Bioethics; Evaluation

Face ao exposto, levou o paciente a questão à Justiça sob a alegação de dano médico provocado por ignorância e imperícia.

Os peritos nomeados pelo judiciário deram plena razão ao paciente, sendo os médicos condenados ${ }^{(1)}$.

Na Alemanha, mais precisamente no "Reichsgericht" -TRIBUNAL- em 1894, ficou expressamente decidido que a não autorização do paciente era impedimento absoluto à realização de qualquer ato médico, podendo ir para a prisão o profissional que desafiasse tal decisão.

Em 1914, em Nova Iorque (EUA), uma decisão judicial foi primordial no direito do paciente com o reconhecimento de que o mesmo poderia rejeitar o tratamento que lhe fosse proposto. Foi o primeiro processo envolvendo um paciente e uma unidade hospitalar ${ }^{(2)}$.

Advogado (OAB-RJ 70.640) Interno de Medicina da Unigranrio (4599064)

Instituição de ensino: UNIGRANRIO - Universidade do Grande Rio

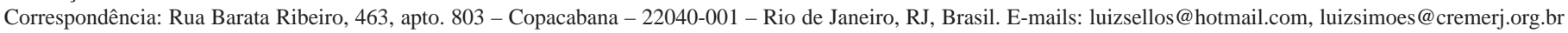
e luizsellos@gmail.com 
O termo Consentimento Informado foi utilizado pela primeira vez em sentença nos Estados Unidos em 1957, na Califórnia.

Dois anos antes o estado norte-americano da Carolina do Norte em sua Suprema Corte já havia definido como negligente a conduta médica de não dar informações sobre os riscos de um procedimento cirúrgico ${ }^{(3)}$.

\section{CONCEITO}

No Brasil, hoje, definimos consentimento informado, como: "trata-se de uma decisão voluntária, verbal ou escrita, protagonizada por uma pessoa autônoma e capaz, tomada após um processo informativo, para aceitação de um tratamento específico ou experimentação, consciente de seus riscos, benefícios e possíveis consequências”(4).

Assim, a obtenção do consentimento do paciente para a realização de um determinado ato médico se traduz em uma concordância, revogável a qualquer instante, precedida de uma informação com clareza, referindo-se a um determinado momento, abrangente e satisfatória para o entendimento de sua real condição de saúde.

É o consentimento informado, um direito do paciente, incluído nos direitos de personalidade, expressando a autonomia - o contrário de heteronomia, em que prevalece a vontade do médico - do paciente em relação a sua integridade física e psicológica, e que se manifesta com o poder de se decidir esclarecidamente acerca de concordância com o tratamento ou a respeito do diagnóstico médico.

Em situações como doenças graves ou, no caso de diagnósticos e tratamentos que possam se prolongar no tempo, o contato entre o médico e o paciente ou seu responsável, com o objetivo de transmitir-lhe informações, esclarecendo-o, sobre a sua situação clínica, não deve ficar circunscrito a uma entrevista.

Também, é necessário que se adaptem as informações fornecidas aos possíveis quadros psicológicos dos pacientes, que venham a ocorrer, naquele determinado momento.

O paciente, ao decidir em relação aos rumos de seu tratamento, não pode se falar em decisão consciente e voluntária, quando a vontade está eivada em um vício como a ignorância. Em caso de ignorância, há ausência de conhecimento sobre o objeto da decisão que o paciente vai tomar. O consentimento pode ser considerado inválido pela existência desse erro substancial - desconhecimento sobre o que vai decidir - que consiste em uma declaração de vontade pré-redigida e incorreta, sem dar a precisa noção sobre as características de investigação, diagnóstico, tratamento e prognóstico de sua doença ${ }^{(5)}$.

\section{LEGISLAÇÃO VIGENTE NO BRASIL}

A doutrina legal do consentimento informado reportase ao Código de Defesa do Consumidor (CDC), criado pela Lei ${ }^{\circ} 8.078$ de 11 de setembro de 1990, com fulcro no artigo $5^{\circ}$, XXXII da Constituição Federal, aplicáveis onde ocorrer em relações de consumo.

De acordo com o CDC, o paciente é o consumidor para quem se presta um serviço; o médico, o fornecedor que desenvolve atividades de prestação de serviços; e o ato médico, uma atividade mediante remuneração a pessoas físicas ou jurídicas sem vínculo empregatício ${ }^{(6)}$.

A Constituição Federal Brasileira, em vigor desde 1988, atribui caráter de serviço público dos prestadores de serviço face ao que expressa o artigo $6^{\circ}$, "caput”:

"São direitos sociais, a saúde, o trabalho, o lazer, a segurança, a previdência social, a proteção à maternidade e à infância, a assistência aos desamparados, na forma desta Constituição".

Além deste, o artigo 196 também da nossa Magna Carta é contundente:

"A saúde é direito de todos e dever do Estado, garantido mediante políticas sociais e econômicas que visam à redução do risco de doença e de outros agravos e ao acesso universal igualitário às ações e serviços para a sua promoção, proteção e recuperação”. Não deixa, dúvida, o caráter de serviço público, mesmo que concedido a particulares, a atividade de prestação de serviços hospitalares.

Responsabilidade civil é como se impõe a determinada pessoa o reparo a prejuízo causado a outrem, via indenizatória, por fato próprio ou de pessoa ou coisas que dela dependam ${ }^{(7)}$.

Logo, deve ser entendida como um dever jurídico sucessivo que surge para recompor o dano decorrente de um dever jurídico originário ${ }^{(8)}$, ou seja, é subjetiva e o ônus da prova cabe a quem alega, ao não ser requerida a inversão prevista no CDC.

A responsabilidade pessoal dos médicos é subjetiva, mas o ônus da prova fixa sendo a favor do consumidor ${ }^{(6)}$.

Anteriormente ao Código de Defesa do Consumidor (CDC) era princípio consagrado no Direito que o ônus da prova caberia a quem alegasse, porém, hoje, houve a inversão do mesmo, sendo atual a interpretação que (artigo $6^{\circ}$, VIII e 14 do CDC):

"O fornecedor de serviços responde, independente da existência de culpa, pela reparação dos danos causados aos consumidores por defeitos relativos a prestação dos serviços, bem como por informações insuficientes ou inadequadas sobre a fruição e riscos. O parágrafo $4^{\circ}$ impõe que a responsabilidade pessoal dos profissionais 
liberais será apurada mediante a verificação de culpa”; logo, o consentimento informado tornar-se-ia uma importante arma na defesa do médico.

A previsibilidade se configura como vínculo psíquico entre o agente e o resultado, expressa pela ausência de previsão do previsível (consentimento informado), dá o limite da responsabilidade do agente (médico) pelos resultados que decorrem da sua falta de diligência inicial. Só pelos resultados previsíveis responderá o agente, podendo os demais, que não sejam fruto de imperícia, imprudência ou negligência, serem consideradas fatalidades profissionais.

Se eliminarmos o critério de previsibilidade, faremos da culpa simples hipótese de obrigatoriedade condenatória, oposto ao princípio da culpabilidade no sentido subjetivo moderno ${ }^{(9)}$.

Não é suficiente, para que seja exigível a responsabilidade civil, que o paciente haja sofrido um prejuízo, nem que o médico tenha agido com culpa. Deve reunir-se um terceiro e último requisito, a existência de um vínculo de causa e efeito entre a culpa e o dano, é necessário que o dano sofrido seja a consequência da culpa cometida (nexo causal).

Mesmo na responsabilidade objetiva é indispensável o nexo de causalidade entre a conduta e o resultado. Entre as causas que excluem a responsabilidade do médico, está provar que, tendo prestado o serviço o defeito inexiste. Basta que prove que o evento não decorreu de defeito de serviço, mas sim das condições próprias do paciente, onde pode auxiliá-lo o termo de consentimento informado detalhado e cauteloso, ou de outros fatores imprevisíveis ${ }^{(10)}$.

Sendo subjetiva a responsabilidade pessoal do médico, como na realidade o é, não bastará o mero insucesso do tratamento, seja clínico ou cirúrgico, para ensejar o seu dever de indenizar. Caberá a vítima provar não só o dano e o nexo causal, como a responsabilidade objetiva, mas também a culpa do médico. Este ocorre quando empregados os conhecimentos normais de Medicina, por exemplo, chega o médico à conclusão errada de diagnóstico ou de uma intervenção cirúrgica; só a falta grosseira destes profissionais consubstancia a culpa penal ${ }^{(11)}$.

Na responsabilidade objetiva a culpa será provada ou presumida (ex.: falta de consentimento informado em cirurgias eletivas que resultem, por exemplo, em Ortopedia, na limitação dos movimentos de um determinado membro ou diminuição de funções do mesmo), pois no Brasil só se pode condenar alguém a indenizar havendo culpa.

Hoje, com a inversão do ônus da prova, facultado pelo Código de Defesa do Consumidor, cabe ao médico provar a própria inocência e não mais ao paciente a culpa do profissional.
Para que exista o exercício regular de direito é indispensável o consentimento do paciente, conforme o expresso no artigo 46, "caput" do Código de Ética Médica, ou de seu representante legal, o médico tem o dever de dar informação ao paciente e, se não for caso de urgência, o paciente deve ser consultado sobre as opções médicas, para que possa escolher, devendo ser informado e quando possível, consentir no procedimento, sendo plenamente esclarecido também sobre os possíveis riscos da intervenção médica e tudo o que será feito ${ }^{(12)}$.

Apesar do uso do termo de consentimento informado a intervenção médica ou cirúrgica não exclui o crime quando houver imperícia, negligência ou imprudência do agente, respondendo este por delito culposo se não se tratar de simples erro profissional ${ }^{(13)}$.

Esclarece-se que, definem os Dicionários de Língua Portuguesa:

"Imperícia: incompetência, falta de perícia; Imprudência: ato de agir sem os cuidados obrigatórios; Negligência: preguiça, descuido, desleixo"(13,14).

Se o paciente alega um erro médico, a responsabilidade da prova para defender-se pode ser facultativa, se for considerada difícil o usuário pré-constituir prova sobre os seus supostos direitos, até porque ele, no momento da relação, está em sua boa-fé, além dos imagináveis obstáculos para obter material probatório. (prontuário médico).

As sanções aplicadas pelo Código de Defesa do Consumidor, além da multa, estão previstas no artigo 56:

"As infrações das normas de defesa do consumidor ficam sujeitas, conforme o caso, às seguintes sanções administrativas, sem prejuízo das de natureza civil, penal e das definidas em normas específicas: I - Multa; IV Suspensão do fornecimento de serviços; IX - Cassação da licença do estabelecimento ou de atividade.

As sanções relacionadas serão aplicadas pela autoridade administrativa, no âmbito de sua atribuição (Conselho Regional de Medicina) assegurada a ampla defesa”.

O Código Civil, em seu artigo 951, traz uma ampliação na responsabilidade indenizatória, principalmente no que diz respeito às hipóteses de morte, inabilitação para o trabalho e ferimentos, trazendo como situação nova o agravar do mal do paciente. No caso de ferimento, pode admitir-se também maior abrangência na responsabilidade estudando-se também a causa da lesão no paciente, o que é mais amplo do que o ferimento, abrangendo também, por exemplo, desordens psicológicas entre outras, podendo ser de qualquer ordem (ex.: familiar, social, profissional e etc.), já que não há restrição no texto mencionado.

O Novo Código Civil, de 10 de janeiro de 2003, em seu artigo 206, reza que: 
“Art. 206. Prescreve: $\S 3^{\circ}$ : em três anos: V - a pretensão de reparação civil”.

O Código Civil de 2003 corrobora tal responsabilidade no artigo 927, parágrafo único:

“Art. 927. (...) Parágrafo Único. Haverá obrigação de reparar o dano, independentemente de culpa, nos casos especificados em lei, quando a atividade desenvolvida pelo autor do dano implicar por sua natureza, riscos para os direitos de outrem."

Para que se compreenda a importância do consentimento informado na doutrina jurídica aplicável ao médico é mister que se entenda conceitualmente o dano.

Definir-se-ia dano material como o que afeta fisicamente a pessoa, seus bens corpóreos, ou interesses econômicos (ex.: patrimônio), ao passo que dano moral atinge bem jurídico de ordem moral ou subjetiva, como a honra, a dignidade, a consideração social, de difícil estimativa pecuniária.

\section{ELABORAÇÃO DE UM CORRETO CONSENTIMENTO INFORMADO}

Isto posto, seriam requisitos mínimos a serem considerados em um documento de consentimento informado:

- O nome e sobrenome do paciente e do médico informante;

- Explicação da natureza da enfermidade e sua evolução natural;

- Nome do procedimento a realizar e especificações do que consiste e como será levado a termo;

- Explicação dos benefícios e riscos que razoavelmente se esperam da intervenção e as consequências da denegação;

- Informações sobre os riscos da intervenção, prováveis complicações, mortalidade e sequelas;

- Alternativas de tratamento comparadas ao tratamento proposto;

- Explicação sobre o tipo de medicação exigível para a intervenção e seus riscos;

- Autorização para obter fotografias, vídeos, registros gráficos, antes, durante e após a intervenção, para difundir os resultados ou iconografia em revistas médicas e/ou nos âmbitos científicos;

- Possibilidade de revogação do consentimento em qualquer momento antes da intervenção;

- Satisfação do paciente pela informação recebida e afastamento de todas as suas dúvidas;

- Tudo isso em uma linguagem simples e de fácil acesso, para a plena compreensão do paciente e/ou seus familiares;

- Assinatura do médico, do paciente e das testemunhas, se possível acrescidas do número das respectivas identificações civis (ex.: identidade, CPF, endereço e etc.) ${ }^{(15)}$.

\section{MÉTODOS}

Aplicando-se o método dialético, parte-se da análise da legislação brasileira em vigor que abrange o tema da obrigação ou não do uso do termo de consentimento informado, partindo, em seguida, à observação direta extensiva das jurisprudências emitidas pelo Tribunal de Justiça do Estado do Rio de Janeiro durante o ano de 2008, exclusivamente.

Foram pesquisados quantitativamente 269 Recursos Cíveis Indenizatórios motivados por supostos erros médicos, destacando-se como parâmetros o número de absolvições ou condenações de médicos e/ou instituições nas quais trabalham ${ }^{(16)}$.

Consideraram-se nas pesquisas o uso ou não pelos médicos e magistrados do consentimento informado, seja como fonte de defesa quanto para a elaboração de sentenças, cujo respaldo da condenação se dê por alegado desconhecimento de resultados desagradáveis obtidos após a realização de um determinado procedimento médico.

Destacou-se, também, dentro do mesmo universo processual, cujas sentenças fundamentam-se nas leis e protocolos descritos na introdução, a realidade específica dos médicos ortopedistas dando-lhes especial tratamento e atenção o presente trabalho.

A pesquisa foi realizada junto à internet, no site do supracitado tribunal, em artigos científicos e na literaturas brasileira e estrangeira técnicas de corrente de estudos dominante em nossos dias.

\section{RESULTADOS}

Ao contrário do que se pensa a grande maioria dos médicos, o judiciário não lhes é tão severo ou impositivo, procurando, ao invés disso, a versão mais próxima a verdade médica e compreendendo com perfeição a profissão, seus anseios, suas aspirações e entendendo com clareza as suas dificuldades e intercorrências profissionais, esperando dos mesmos que estes busquem sempre o melhor restabelecimento, quando possível, de seu paciente, dentro da terapêutica adequada a bons padrões acadêmicos.

\section{DISCUSSÕES}

A prova disso é que, contando-se inclusive os processos extintos sem julgamento do mérito, havia 194 absolvições, no universo dos 269 recursos cíveis julgados pelo Tribunal de Justiça do Estado do Rio de Janeiro, em sua maioria esmagadora sob o argumento de falta de nexo causal proposto na petição inicial e a real conduta médica, aferida por perícia judicial. 
Exemplificando o nexo causal, de forma simples teríamos, um homem portador de aneurisma cerebral morre em queda de avião onde realizava viagem comercial. Conclui-se que não há nexo causal entre o aneurisma, que seria a sua doença e a causa de sua morte, que é o acidente aéreo.

Ressaltam-se que duas destas absolvições, tiveram como causa o bom e razoável uso do termo de consentimento informado, antecedendo ao procedimento médico, atendendo aos dispositivos já expostos na introdução.

As condenações, em número de 24 , deram-se, em sua maioria por óbito do paciente não observando-se protocolos médicos mínimos, isso, em grande parte aferido pela não descrição precisa da totalidade dos atos médicos no prontuário ${ }^{(17)}$, além de cinco processos terem sido gerados especificamente pelo paciente alegar desconhecer as futuras consequências do ato médico ao qual foi submetido, ou seja, o termo de consentimento informado feito anteriormente ao procedimento, poderia evitar a condenação civil.

No montante processual supracitado, havia 13 processos específicos contra ortopedistas, resultando em nove absolvições e quatro condenações, porém nenhuma que pudesse ser vinculada ou não ao uso do termo de consentimento informado.

O restante dos processos por erro médico, não satisfazia ao presente estudo, uma vez que eram direcionados contra plano de saúde, seguros de vida e outros, totalizando estes 51 processos.
Observadas as indenizações nos processos condenatórios, vislumbramos o patamar mínimo de um salário mínimo, um máximo de $\mathrm{R} \$ 200$ mil e uma média oscilando entre $\mathrm{R} \$ 30$ mil e $\mathrm{R} \$ 40$ mil, respondendo por estas os médicos e as instituições em que trabalham conjuntamente $\mathrm{e}^{(17)}$, sejam elas públicas, particulares e/ ou filantrópicas.

\section{CONCLUSÃO}

Embora o consentimento informado ainda tenha uso embrionário em nossos meios médico-jurídicos, este tem pleno amparo legal, já contando com o apoio de muitos médicos e juristas, devendo vir a se formar, por força das leis já existentes, prática corriqueira no exercício médico jurídico, assim como elemento componente na formação de convicção dos magistrados na elaboração de seus julgados.

O mero uso desse termo não isenta quanto a aplicação da lei nos erros por imperícia, imprudência ou negligência do profissional, nem dos processos médicos por tais atos, mas seus supostos erros podem ser descartados com razoável confiabilidade quando utilizados os meios acadêmicos adequados para o caso de cada paciente, associando-se a informação plena do mesmo, fato que torna-se inquestionável pela confecção de um termo consentimento informado redigido de forma honesta, clara, simples e transparente, salvaguardando o médico de pesadas indenizações aplicadas pela Justiça.

\section{REFERÊNCIAS}

1. Goldim JR. Primeira sentença judicial sobre a necessidade do uso de consentimento. Núcleo Interinstitucional de Bioética da Universidade do Rio Grande do Sul / Hospital das Clínicas de Porto Alegre. Disponível em: http://www.ufrgs. br/bioetica/conslate.htm. Acesso em 15 mai 2009.

2. Silva CA. O consentimento informado e a responsabilidade civil do médico, Jus Navigandi, Terezina, a. 7, n. ${ }^{\circ} 63$ mar 2003. Disponível em: http://jus2.uol.com. br/doutrina/texto.asp?id=5311. Acesso em 25 abr 2009.

3. Clotet J. O consentimento informado: uma questão de interesse de todos. Jornal de Medicina, do Conselho Federal, (10/11); 2000. p. 9.

4. Souza NTC. Erro médico e consentimento informado, Jus Navigandi, Terezina, ano 8. n. ${ }^{\circ} 337,9$ jun 2004. Disponível em: http://jus2.uol.com.br/doutrina/texto. asp?id=5311. Acesso em 26 abr 2009.

5. Biondo-Simões MLP, Martynetz J, Ueda FMK, Olandoski M. Compreensão do termo de consentimento informado. Rev Col Bras Cir. 2007:34(3):183-8.

6. Código de defesa do consumidor. 9a. edição. Rio de Janeiro: Forense; 2007. p. $21 ; 193$.

7. Cavallieri S. Programa de responsabilidade civil. 6a. edição. São Paulo: MaIheiros; 2005. p. 25

8. Coutinho LM. Código de ética médica comentado. 3a. edição. Florianópolis: Editora OAB/SC; 2003. p.153.

9. Anibal B. Direito penal: parte geral. 4a. edição. Rio de Janeiro: Forense; 1984. p.138.

10. Foster N. Erro médico. São Leopoldo: Editora Unisinos; 2002. p. 39.

11. Udesmann A. Responsabilidade civil, penal e ética dos médicos. Rev Assoc Med Bras. 2002;48(2):172-82.

12. Mirabete JF. Manual de direito penal. 20ª edição. São Paulo: Editora Atlas; 2003. p. 192.

13. Ferreira, $A B H$. Mini Aurélio séc. $X X I$ - Minidicionário da Língua Portuguesa $4^{\text {a }}$ Edição especial para o FNDE/PNLD-Editora Nova Fronteira-2002.

14. Neves LB. Vocabulário prático de tecnologia jurídica e de brocados latinos. $2^{a}$ edição. Rio de Janeiro: Edições Fase; 1988.

15. Navarro-Reynoso FP, et al. Derechos humanos y consentimiento informado. Cirurgia y Cirurjanos, México. 2004;72(3):243. Disponível em: http://medigraphic. com/espanol/e-htms/e-circir/e-cc2004/e-cc04-3/em-cc043n.htm. Acesso em 27 mai 2009.

16. Tribunal de Justiça do Estado do Rio de Janeiro. Consultas a jurisprudências ano início: 2008 - ano término: 2008, tema: Erro Médico. Disponível em: http:// www.tj.rj.gov.br. Acesso 01 mai 2009

17. Código Civil Brasileiro. 54ª edição. São Paulo: Editora Saraiva; 2003. p.69. 